\title{
Environmental Enrichment During Early Stages of Life Reduces the Behavioral, Neurochemical, and Molecular Effects of Cocaine
}

\author{
Marcello Solinas', Nathalie Thiriet', Rana El Rawas', Virginie Lardeux' and Mohamed Jaber*,' \\ 'Institut de Physiologie et Biologie Cellulaires, University of Poitiers, CNRS, Poitiers, France
}

\begin{abstract}
It is known that negative environmental conditions increase vulnerability to drugs, whereas little is known on whether positive environmental conditions such as enriched environments (EE) have protective effects against addiction. We have previously found that EE consisting of bigger cages containing several toys that were changed once per week reduce cocaine-induced increases in locomotor activity. Here, we also show that the rewarding effects of cocaine are blunted in mice reared from weaning to adulthood in EE compared to mice reared in standard environments (SE). In addition, although both EE and SE mice develop behavioral sensitization to cocaine, EE mice show less activation in response to repeated administration of cocaine injections and reduced responses to cocaine challenges. In vivo microdialysis experiments demonstrate that the protective effects of EE do not depend on reduced cocaine-induced increases in the dopamine levels in the ventral or dorsal striatum. On the other hand, they were associated with reduced cocaine-induced expression of the immediate early gene zif-268 in the nucleus accumbens (shell and core) of EE mice. Finally, basal levels of Delta-Fos B, a transcription factor known to be increased by sustained activation of striatal neurons, are higher in the striatum of EE compared to SE mice and repeated administration of cocaine increases Delta-Fos B levels in SE mice but decreases them in EE mice. Altogether our results demonstrate that exposure to complex environments during early stages of life produce dramatic changes in the striatum that result in reduced reactivity to drugs of abuse.

Neuropsychopharmacology (2009) 34, I I02-I I I ; doi: I0.1038/npp.2008.5 I; published online 7 May 2008
\end{abstract}

Keywords: addiction; enrichment; behavior; dopamine; nucleus accumbens; molecular biology

\section{INTRODUCTION}

Of the many people who experience psychoactive drugs, only a small percentage develops drug addiction. It is believed that environmental factors play a central role in determining sensitivity to the rewarding effects of drugs and vulnerability to develop addiction (Sinha, 2001; Goeders, 2002; Marinelli and Piazza, 2002; Kreek et al, 2005). For example, several studies have demonstrated that environmental stressors increase the unconditioned, conditioned, and reinforcing effects of drugs such as amphetamine, cocaine, and heroin (Sinha, 2001; Goeders, 2002; Marinelli and Piazza, 2002; Kreek et al, 2005). Preclinical studies have also provided important information on the mechanisms underlying this enhanced response to the effects of drugs and have shown that the dopamine

*Correspondence: Professor M Jaber, Institut de Physiologie et Biologie Cellulaires, University of Poitiers, CNRS-6187, 40 avenue du recteur Pineau, Poitiers 86022, France, Tel: + 33 (0)5 49453985 ,

Fax: + 33 (0)5 49 4540।4, E-mail: mohamed.jaber@univ-poitiers.fr Received 25 January 2008; revised 4 March 2008; accepted 5 March 2008 system is implicated in this excessive reaction to drugs (Rouge-Pont et al, 1995; Goeders, 2002; Marinelli and Piazza, 2002).

The investigation of negative factors exacerbating addiction has been extensive, whereas considerably less attention has been dedicated to environmental manipulations that may mimic positive life experiences such as enrichment environments (EE) and may provide protection against drugs' effects. EE have been shown to increase learning and memory (van Praag et al, 2000), to facilitate recovery from brain injuries (Will et al, 2004), to reduce the insurgence of neurodegenerative diseases (Nithianantharajah and Hannan, 2006) and some authors have suggested that EE represent more natural and healthy environment than current standard housing conditions (Wurbel, 2001). In addition, some studies have shown that the reinforcing effects of amphetamine and nicotine are reduced in rats reared in $\mathrm{EE}$ compared to rats reared in social isolation (Bowling et al, 1993; Bardo et al, 2001; Green et al, 2002, 2003).

In a previous study, we have shown that mice reared in EE show less locomotor activity and a different pattern of c-fos activation in the striatum in response to an acute 
injection of cocaine compared to mice reared in a standard environments (SE) (Bezard et al, 2003). We also found that EE mice had less dopaminergic neurons in the substantia nigra pars compacta, lower levels of the dopamine transporter (DAT), the molecular target of cocaine, and higher levels of neurotrophin BDNF in the striatum (Bezard et al, 2003). These findings provided an initial demonstration that EE may be crucial in determining resistance to drugs of abuse such as cocaine. However, little information is available on the effects of EE on cocaine's rewarding properties, which are considered directly responsible for the development of drug addiction and on the behavioral and molecular consequences of repeated administration of cocaine.

In this study, we housed mice either in EE or SE from weaning to adulthood and we used (1) conditioned place preferences (Cunningham et al, 2006) to assess the rewarding effects of cocaine; (2) behavioral sensitization, an animal model for the intensification of drug craving and relapse believed to underlie addiction in humans (Vanderschuren and Kalivas, 2000; Robinson and Berridge, 2003; Bradberry, 2007), to assess the consequences of repeated exposure to cocaine; (3) in vivo microdialysis techniques to assess the response to cocaine of the dopamine mesolimbic system at the presynaptic level (Di Chiara and Bassareo, 2007); (4) in situ hybridization techniques to assess the reactivity to cocaine of the dopamine mesolimbic system at the postsynaptic level by measuring expression of immediate early genes (Hope, 1998; Berke and Hyman, 2000; Gerfen, 2000) and (5) western blot techniques to assess whether the differences observed in the behavioral effects of cocaine could be due to changes in the levels of Delta-Fos B, a transcription factor that is implicated in long-term neuroadaptations associated with drug addiction (McClung et al, 2004).

\section{MATERIALS AND METHODS}

\section{Subjects}

Male $\mathrm{C} 57 \mathrm{Bl} / 6 \mathrm{~J}$ mice (Janvier, France) were housed in a temperature-controlled environment on a 12-h light/dark cycle with the lights on from 0700 to 1900 hours and had ad libitum access to food and water. All experimentation was conducted during the light period. Experiments were carried out in accordance with the European Communities Council Directive of 24 November 1986 (86/609/EEC) for the care of laboratory animals.

\section{Housing Environmental Conditions}

After weaning ( 3 weeks of age), mice were randomly divided in two different housing environmental conditions: SE or EE. SE consisted of common cage housing $(25 \times 20 \times$ $15 \mathrm{~cm})$. The EE consisted of larger $(60 \times 38 \times 20 \mathrm{~cm})$ cages containing a constantly running wheel and a small house and four-five toys that were changed once a week with new toys of different shape and color. For both SE and EE conditions, mice were housed in groups of four (each mouse from a different sibling) for at least 2 months and maximum 3 months before the start of the experiments. All the experiments were conducted at adulthood.

\section{Conditioned Place Preference}

Conditioned place preference experiments were performed in four identical boxes (IMETRONIC, Pessac, France) formed by two lateral chambers $(15 \times 15 \times 20 \mathrm{~cm})$ connected by a central alley $(5 \times 15 \times 20 \mathrm{~cm})$. Two sliding doors separated the alley from the chambers. In each chamber, two Plexiglas prisms with triangular bases $(5 \times 7 \times 19 \mathrm{~cm})$ were arranged to form different patterns (always covering the same surface of the chamber) and were used as conditioned stimuli. Two different metallic grids, one with large $(1 \mathrm{~cm})$ squares and the other with small $(0.5 \mathrm{~cm})$ circles were also used as conditioned stimuli. Behavioral data were collected by an Imetronic interface connected to a PC. Two infrared photocells were present in each compartment and detected the presence and movements of mice. Conditioned place preference procedure consisted of three phases: preconditioning, conditioning, and test. For each manipulation, mice were brought to the experimental room $60 \mathrm{~min}$ before the start of the experiment to allow for habituation and to reduce stress. Preconditioning was performed on day 1 . Mice were placed in the central compartment with the doors closed. After $15 \mathrm{~s}$, the doors were opened and mice were free to explore the entire twocompartment apparatus for $20 \mathrm{~min}$. The time spent in each compartment was recorded and was considered a measure of spontaneous preference. Conditioning sessions were performed on days 2, 3, and 4, twice per day with morning and afternoon sessions separated by at least $6 \mathrm{~h}$. During these sessions, mice were injected with either saline or cocaine (10 and $20 \mathrm{mg} / \mathrm{kg}$ ) and immediately confined to one of the pairing compartments for $30 \mathrm{~min}$. The order of treatments (saline or cocaine), the time of cocaine injection (morning or afternoon), and the compartment (right or left) were counterbalanced in a semirandom order in both SE and EE mice. Control mice received saline on both sides of the cage. A total of three cocaine- and three salineconditioned sessions were performed. Test sessions for conditioned place preference were conducted on day 6 and were similar to preconditioning sessions with animals placed in the central compartment for $15 \mathrm{~s}$ and then left free to choose a compartment for $20 \mathrm{~min}$. The time spent in each compartment was measured and compared to the time spent in the same compartment during the preconditioning session. Preference scores, which served as a measure of rewarding effects of cocaine, were calculated by subtracting the time in seconds spent during the pretest from the time spent during the test day in the compartment paired to cocaine injections. For saline-saline groups, given that there was not a natural preference for either compartment, we arbitrarily chose to calculate preference score in the left compartment. We also verified that results would not have been different if we had chosen to calculate preference scores for the right compartment.

\section{Locomotor Activity and Behavioral Sensitization Procedure}

Motor activity was measured in Plexiglas cages $(19 \times 11 \times$ $14 \mathrm{~cm}$ ) placed in frames mounted with computer-monitored photocell beams (IMETRONIC). Horizontal locomotion was measured by the number of cage crossings. Behavioral data 
were collected by an Imetronic interface connected to a PC. Mice were first habituated to locomotor chambers for $60 \mathrm{~min}$. Then, they were injected intraperitoneally with drug or saline and immediately placed back into the chamber.

Behavioral sensitization consisted of two phases: development and expression. For development of behavioral sensitization six injections of cocaine $(15 \mathrm{mg} / \mathrm{kg}$ intraperitoneally (i.p.)) or saline were administered every second day. Expression of behavioral sensitization was measured 30 days after the last injection (withdrawal day 30). A total of eight groups were obtained ( $N=8$ per group): SE sal-sal; sal-coc; coc-sal and coc-coc and EE sal-sal; sal-coc; cocsal and coc-coc. Sal-sal mice received saline both during development and expression of behavioral sensitization; sal-coc mice received saline during development and cocaine for the expression of behavioral sensitization; coc-sal mice received cocaine during development and saline for the expression of behavioral sensitization; $\operatorname{coc}-\operatorname{coc}$ mice received cocaine both during development and expression of behavioral sensitization. Locomotor activity was measured for $90 \mathrm{~min}$ for cocaine during the development of behavioral sensitization. On withdrawal day 30 , locomotor activity was measured for only $45 \mathrm{~min}$ to allow the killing of mice and for obtaining brains to perform in situ hybridization studies.

\section{In Vivo Microdialysis}

Two groups of SE and two groups of EE mice $(N=5-6$ per group) were used for in vivo microdialysis experiments. Concentric dialysis probes design was similar to the one previously described for rats (Solinas et al, 2006), but sizes were adapted for mice. The exposed dialyzing surface of the probes was limited to the lowest $1.0 \mathrm{~mm}$ portion of the probes. Probe diameter was $0.250 \mathrm{~mm}$. Mice were deeply anaesthetized with Avertin $(0.4-0.75 \mathrm{mg} / \mathrm{g})$ and placed in a stereotaxic apparatus (Stoelting Co., Illinois, USA). Coordinates for the nucleus accumbens (NAc) $(A=1.5 ; L=0.6 ; V=5.0)$ and caudate putamen $(A=0.0$; $L=1.8 ; V=4.0)$ were in accordance with the mouse brain atlas (Paxinos and Franklin, 2001). Each mouse was implanted with a single probe in the left hemisphere. About $24 \mathrm{~h}$ after probe implant, experiments were performed in freely moving mice. Ringer's solution $(147.0 \mathrm{mM} \mathrm{NaCl}$, $2.2 \mathrm{mM} \mathrm{CaCl}_{2}$, and $4.0 \mathrm{mM} \mathrm{KCl}$ ) was delivered through the dialysis probes at a constant flow rate of $1 \mu \mathrm{l} / \mathrm{min}$. Dialysate samples $(20 \mu \mathrm{l})$ were collected every $20 \mathrm{~min}$ and $10 \mu \mathrm{l}$ were immediately injected for analysis by high-performance liquid chromatography (5200a Coulochem III, ESA, Chelmsford, MA, USA). The mobile phase contained $100 \mathrm{mM}$ $\mathrm{NaH}_{2} \mathrm{PO}_{4}, 0.1 \mathrm{mM} \mathrm{Na}{ }_{2}$ EDTA, $0.5 \mathrm{mM}$ n-octyl sulfate, and $18 \%(\mathrm{v} / \mathrm{v})$ methanol ( $\mathrm{pH}$ adjusted to 5.5 with $\mathrm{Na}_{2} \mathrm{HPO}_{4}$ ). After stable dopamine level values (less than $10 \%$ variability) were obtained for at least three consecutive samples (typically after about $3 \mathrm{~h}$ ), treatments started. Mice were first injected with saline and dopamine levels monitored for $60 \mathrm{~min}$, then with $10 \mathrm{mg} / \mathrm{kg}$ of cocaine and dopamine levels monitored for $120 \mathrm{~min}$ and, finally, with $20 \mathrm{mg} / \mathrm{kg}$ of cocaine and dopamine levels monitored for $120 \mathrm{~min}$. Assay sensitivity for dopamine was 2 fmoles per sample. At the end of the microdialysis experiments, mice were euthanized by dislocation and brains were removed and left to fix in $4 \%$ formaldehyde in saline solution. Brains were then frozen and cut on a cryostat in serial coronal slices. Slices were colored with cresyl violet to identify the location of the probes (see Supplementary Figures S1 and S2). Only data from mice with correct probe location were considered for statistical analysis. Dopamine levels are expressed as a percentage of basal dopamine values. Basal dopamine values were calculated as the mean of three consecutive samples (differing no more than $10 \%$ ) immediately preceding the first drug or vehicle injection.

\section{In Situ Hybridization}

In situ hybridization experiments were performed on the brain of mice sensitized as described above. The same eight experimental groups were analyzed: SE sal-sal; sal-coc; coc-sal and $\operatorname{coc}-\operatorname{coc}$ and EE sal-sal; sal-coc; coc-sal and $\operatorname{coc}-\operatorname{coc}(N=6$ per group). Mice were killed $45 \mathrm{~min}$ after the last injection of cocaine at day 30 of withdrawal. This postmortem time was chosen because levels of immediate early genes peak within an hour after cocaine injections (Yano and Steiner, 2005). Brains were removed, frozen in isopentane at $-40^{\circ} \mathrm{C}$, and then stored at $-80^{\circ} \mathrm{C}$. Coronal tissue sections $(14 \mu \mathrm{m}$ thick) were thaw mounted onto SUPERFROST slides (VWR International, Fontenay sous Bois, France) and stored at $-80^{\circ} \mathrm{C}$.

In situ hybridization was performed with $\left[{ }^{35} \mathrm{~S}\right]$ (UTP)labeled RNA for zif-268 (Thiriet et al, 2002). Sections were delipidated, acetylated $(0.25 \%$ acetic anhydride in $0.1 \mathrm{M}$ triethanolamine $(\mathrm{pH} 8)$ ), prehybridized for $10 \mathrm{~min}$ at $60^{\circ} \mathrm{C}$ in $50 \%$ formamide/SSC $1 \times(150 \mathrm{mM} \mathrm{NaC1}$ and $15 \mathrm{mM}$ sodium citrate, $\mathrm{pH} 7$ ), dehydrated and air-dried. Thirty microliters of the labeled probes diluted to $25000 \mathrm{cpm} / \mu \mathrm{l}$ with hybridization buffer (50\% formamide, $10 \%$ dextran sulfate, SSC $4 \times, 10 \mathrm{mM}$ dithiothreitol) was placed on tissue sections and covered with coverslips and left overnight at $52^{\circ} \mathrm{C}$. Post-hybridization was then carried out as previously described (Thiriet et al, 2002). The sections were exposed to $\mathrm{X}$-ray film (Kodak, biomax-MR) for 4 days, then 7 days to Storm phosphorimager system for quantitative analysis using Image Quant software. Optical densities for each area (see Supplementary Figure S3) were calculated by subtracting to all areas the background level determined between sections of each slide. A total of two slides per animal (four sections per slide) were used for each hybridization experiment. All experiments were duplicated.

\section{Western Blot}

To measure Delta-Fos B $(35-37 \mathrm{kDa})$ protein levels in the striatum, mice were exposed to the same regimen for the development of cocaine sensitization used for behavioral and in situ hybridization experiments. A total of four groups were used: SE sal, SE coc, EE sal and EE $\operatorname{coc}(N=12$ per group). Sal groups received six injections of saline, whereas coc groups received six injections of $15 \mathrm{mg} / \mathrm{kg}$ of cocaine every second day. Mice were killed by decapitation $18 \mathrm{~h}$ after the last injection because the levels of Delta-Fos B are maximal, whereas other Fos proteins are absent at this time point (McClung et al, 2004). Brains were immediately removed and striata (NAc and caudate putamen) were immediately dissected. Proteins were extracted using a 
slightly modified version of the protocol described by Brenhouse and Stellar (2006). Briefly, brain tissue was homogenized in boiling lysis buffer $(350 \mu \mathrm{l}$ for $25 \mathrm{mg})$ containing $50 \mathrm{mM}$ Tris- $\mathrm{HCl} \mathrm{pH} 6.8,100 \mathrm{mM}$ DTT, 2\% SDS, with $0.05 \mathrm{U}$ aprotinin $\mathrm{A}, 1 \mu \mathrm{M}$ pepstatin, $1 \mu \mathrm{M}$ leupeptin, $0.1 \mathrm{mM}$ benzamidine, $10 \mathrm{nM}$ chloroquin, $10 \mathrm{nM}$ Soybean Trypsin inhibitor, $0.1 \mathrm{mM} N_{\alpha}$-Tosyl-L-lysine chloromethyl ketone hydrochloride, $100 \mu \mathrm{g} / \mathrm{ml} \quad N_{\alpha}$-p-Tosyl-L-arginine methyl ester hydrochloride, and $0.1 \mathrm{mM}$ PMSF protease inhibitors. After homogenization using ultra-turrax for $15 \mathrm{~s}$ (IMLAB Laboratories technology, France), samples were then boiled for $3 \mathrm{~min}$ and centrifuged at full speed for $10 \mathrm{~min}$. Supernatant were collected and then stored at $-20^{\circ} \mathrm{C}$ until analysis. Protein samples (about $30 \mu \mathrm{g}$ ) were subjected to SDS-polyacrylamide gel electrophoresis ( $10 \%$ acrylamide $/ 0.27 \% N, N^{\prime}$-methylenebisacrylamide resolving gel) and proteins were transferred to PVDF membrane. Blots were blocked for $1 \mathrm{~h}$ in $5 \%$ nonfat dry milk in TBS-Tween $0.1 \%$. Primary antibody incubation was then performed in blocking buffer for $120 \mathrm{~min}$ at room temperature, using rabbit Fos-related antigen (FRA, dilution 1:500), which recognizes the Delta-Fos B isoforms (kindly provided by Dr Iadarola, National Institute of Dental and Craniofacial Research, National Institute of Health, USA). The blots were then washed $3 \times 10 \mathrm{~min}$ in blocking buffer and were subsequently incubated for $60 \mathrm{~min}$ in a $1: 1000$ dilution of goat anti-rabbit antibody conjugated to horseradish peroxidase (Bio-Rad Laboratories, France) in blocking buffer. The blots were then washed again $2 \times 10 \mathrm{~min}$ in blocking buffer and then for $10 \mathrm{~min}$ in TBS, and developed with an enhanced chemiluminescence system (Pierce, France) before being exposed to Kodak MS Film (VWR, France) for $1 \mathrm{~min}$. The blots were subsequently incubated with an anti- $\alpha$-tubulin antibody (1/2000, Sigma-Aldrich, France). Levels of band density were quantified by densitometry with the VisioLab 2000 image analyser (Biocom, Paris, FRANCE), and for each sample the results are expressed as level of delta-Fos B over level of $\alpha$-tubulin. The experiment was repeated twice (each time with $N=6$ for each group). Care was taken to assure that quantification was performed within a linear range (Jaber et al, 1999). As relative values among experimental groups did not vary, data were pooled together by normalizing data to the mean value of each SE saline-treated group.

\section{Drugs}

Cocaine $\mathrm{HCl}(15 \mathrm{mg} / \mathrm{kg}, 10 \mathrm{mg} / \mathrm{kg})$ was obtained from the Research Triangle Institute (Research Triangle Park, NC, USA). It was dissolved in sterile saline solutions (0.9\%) and administered i.p. in a volume of $1 \mathrm{ml} / 100 \mathrm{~g}$.

\section{Statistics}

All results are presented as group means \pm SEM. Differences in behavioral scores, in the levels of extracellular dopamine, mRNA and protein expression between groups were assessed by one, two or three way analysis of variance ANOVA. Results showing significant overall changes were subjected to Student-Newman-Keuls post-hoc test. Differences were considered significant when $p<0.05$.

\section{RESULTS}

\section{EE Mice are Less Sensitive than SE Mice to the Reinforcing Effects of Cocaine}

Neither SE nor EE mice showed significant natural preferences for either conditioned place preference compartments during pretests or developed preferences for one or the other compartment when saline was given in both compartments (Figure 1a and b). On the other hand, SE mice developed significant place preferences to cocaine at the dose of 10 and $20 \mathrm{mg} / \mathrm{kg}$, whereas EE mice did not develop significant preferences at either doses (Figure 1b) (two-way ANOVA, environment effect, $\mathrm{F}(1,67)=5.93, p<0.05$; dose effect, $\mathrm{F}(2,67)=8.27, p<0.01$; environment effect $\times$ dose interaction, $\mathrm{F}(2,67)=2.18, p>0.05)$.

EE Mice are Less Sensitive than SE Mice to the Stimulant Effects of Repeated Administration of Cocaine

As previously reported (Bezard et al, 2003), the first injection of cocaine (15 mg/kg i.p.) produces a higher activation

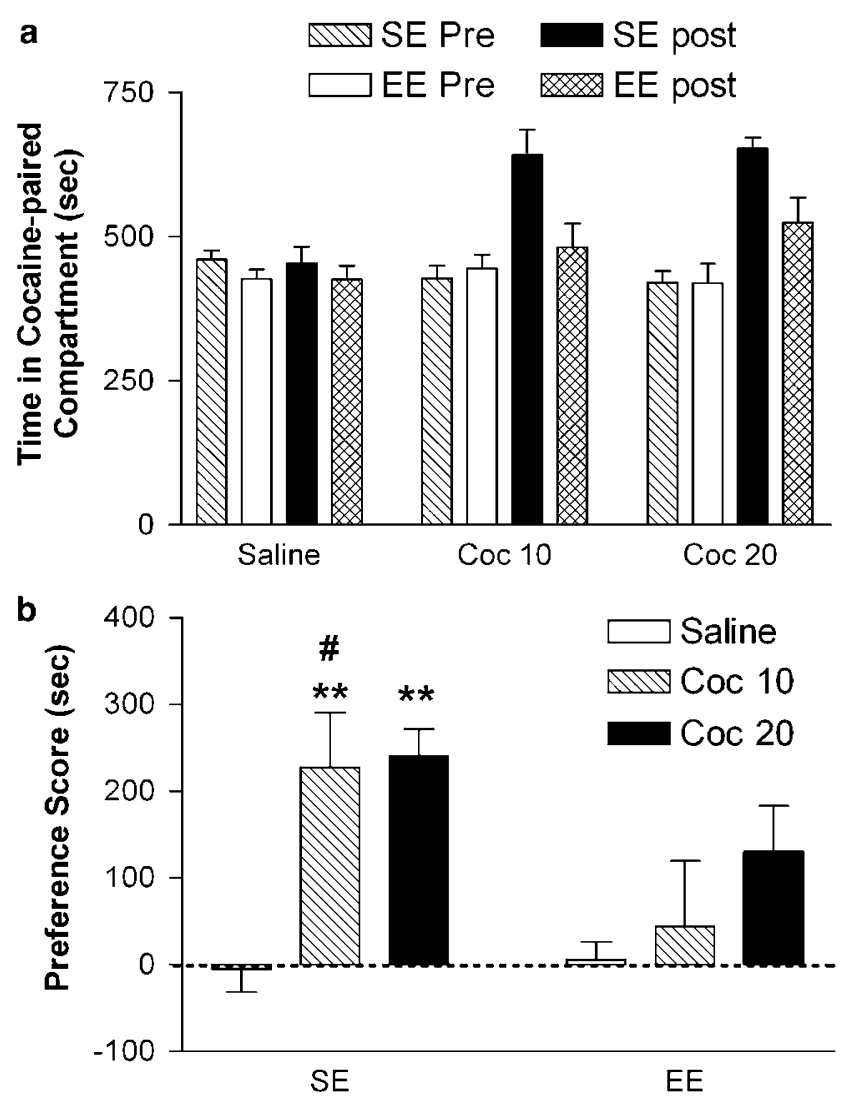

Figure I Rewarding effects of cocaine in mice reared in standard (SE) or enriched (EE) environments. EE and SE mice were tested in the conditioned place preference paradigm after conditioning to cocaine ( 10 and $20 \mathrm{mg} / \mathrm{kg}$ i.p.) or saline. EE showed less conditioned place preference to cocaine than SE mice. (a) Shows time in sec spent in the cocaine-paired compartments before and after conditioning, whereas (b) shows preference scores. Preference score was calculated by the time spent in the cocaine-paired compartment during the test session minus the time spent in the same compartment during the pretest session. Post-hoc Student-Newman-Keuls's test: *** $<0.01$ different from saline control; ${ }^{\#} p<0.05$ EE different from SE mice. Results represent means \pm SEM from | | to 13 mice. 

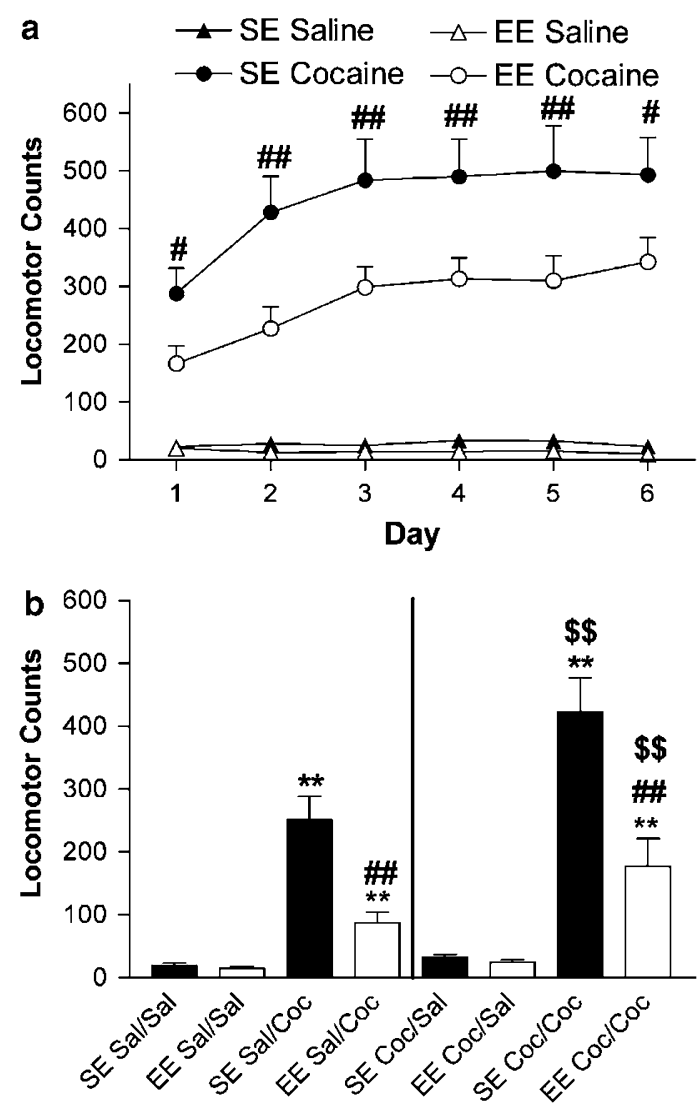

Figure 2 Behavioral sensitization to cocaine in mice reared in standard (SE) or enriched (EE) environments. (a) Development of behavioral sensitization to cocaine ( $15 \mathrm{mg} / \mathrm{kg}$ i.p.). Both SE and EE mice develop behavioral sensitization i.e. cocaine-induce locomotor activity increases over time, but EE consistently show reduced locomotor response to cocaine. (b) Expression of behavioral sensitization to cocaine ( $10 \mathrm{mg} / \mathrm{kg}$ i.p.) after 30 days of withdrawal. Both SE and EE mice show a sensitized response to cocaine (COC-coc vs sal-coc groups) but EE show reduced locomotor response to cocaine compared to SE mice. Post-hoc StudentNewman-Keuls's test: $*$ and $* * * 0.05$ and $p<0.0$ I different from saline control; ${ }^{\# \#} p<0.0$ I different from SE control; ${ }^{\$ \$} p<0.0$ I different from chronic saline control. Results represent means \pm SEM from 15 to 16 mice for panel a and 7-8 mice for panel b. Note that, for clarity, although all data point for the development of cocaine sensitization (panel a) are significantly different from saline controls in both SE and EE mice, symbols are not shown.

in SE mice as compared to EE mice (Figure $2 \mathrm{a}$ and $\mathrm{b}$ ). With repeated administrations, both groups developed sensitization, ie, for both groups the effects of cocaine on day 6 were higher than on day 1 (Figure 2a). However, the effects of cocaine were consistently lower (about 50\%) in $\mathrm{EE}$ compared to SE mice (Figure 2a) (three-way ANOVA, environment effect, $\mathrm{F}(1,59)=3772, p<0.0001$; treatment effect, $\mathrm{F}(1,59)=519.61, p<0.0001$; day effect, $\mathrm{F}(5,354)=13.73$, $p<0.0001$; environment $\times$ treatment interaction, $\mathrm{F}(1,59)=$ $27.79, p<0.0001$; environment $\times$ day interaction, $\mathrm{F}(5,354)=$ $0.22, p>0.05$; treatment $\times$ day interaction, $F(5,354)=4.04$, $p<0.01$; environment $\times$ treatment $\times$ day interaction, $\mathrm{F}(5,354)=0.12, p>0.05)$. In addition, sensitization was maintained in the two groups after 30 days of withdrawal from cocaine as demonstrated by the sensitized response to $10 \mathrm{mg} / \mathrm{kg}$ of cocaine (Figure $2 \mathrm{~b}$ ). However, once again, the amplitude of cocaine's effects was higher in SE than in
EE mice (Figure 2b) (three-way ANOVA, environment effect, $\mathrm{F}(1,55)=25.55, p<0.0001$; treatment effect, $\mathrm{F}(1,55)=11.64$, $p<0.01$; challenge effect, $\mathrm{F}(1,55)=103.82, p<0.0001$; environment $\times$ treatment interaction, $\mathrm{F}(1,55)=1.02, p>0.05$; environment $\times$ challenge interaction, $F(1,55)=22.71$, $p<0.0001$; treatment $\times$ challenge interaction $\mathrm{F}(1,55)=8.24$, $p<0.01$; environment $\times$ treatment $\times$ challenge interaction, $\mathrm{F}(1,55)=0.87, \quad p>0.05)$, indicating that environmental effects on repeated cocaine-induced behaviors and neuroadaptations are due to reduced effects of each acute cocaine administration. Motor impairment could not account for the reduced reactivity to cocaine of EE mice, as EE mice perform actually better than SE on a rotarod paradigm (data not shown).

\section{Cocaine-induced Elevation in Dopamine Levels in the NAc do not Differ Between EE and SE Mice}

Dopamine basal levels did not differ between EE and SE mice neither in the NAc $(\mathrm{SE}=46.59 \pm 4.85 ; \mathrm{EE}=47.90 \pm$ $6.71 \mathrm{fmol} / 10 \mu \mathrm{l})$ nor in the Caudate Putamen $(\mathrm{SE}=51.55 \pm$ 4.87; $\mathrm{EE}=52.98 \pm 6.03 \mathrm{fmol} / 10 \mu \mathrm{l})$. Saline injections did not alter extracellular levels of dopamine, whereas cocaine produced dose-dependent and time-dependent increases in dopamine levels both in the NAc and in the Caudate Putamen (three-way ANOVA for repeated measures, NAc: dose effect, $\mathrm{F}(1,40)=21.28, p<0.0001$; time effect $\mathrm{F}(5,40)$ $=37.77, p<0.0001$; dose $\times$ time interaction $\mathrm{F}(5,40)=7.23$, $p<0.0001$; Caudate Putamen, dose effect, $\mathrm{F}(1,40)=6.31$, $p<0.05$; time effect $\mathrm{F}(5,40)=16.88, p<0.0001$; dose $\times$ time interaction $\mathrm{F}(5,40)=2.07, p>0.05$ ) (Figure 3). Increases in the NAc were more pronounced than those in the Caudate Putamen at both $10 \mathrm{mg} / \mathrm{kg}$ (300 vs $200 \%$ of basal levels) and $20 \mathrm{mg} / \mathrm{kg}$ (450 vs $300 \%$ of basal levels) of cocaine. Importantly, cocaine-induced elevations in extracellular levels of dopamine did not differ in EE and SE mice (three-way ANOVA for repeated measures, NAc: environment effect, $\mathrm{F}(1,40)=0.34, p>0.05$; environment $\times$ dose interaction, $\mathrm{F}(5,40)=0.002, p>0.05$; environment $\times$ time interaction, $\mathrm{F}(5,40)=0.35, p>0.05$; environment $\times$ dose $\times$ time interaction, $\mathrm{F}(5,40)=1.68, p>0.05 ; \mathrm{CPu}$ : environment effect, $\mathrm{F}(1,40)=0.01, \quad p>0.05 ; \quad$ environment $\times$ dose interaction, $\mathrm{F}(5,40)=0.01, p>0.05$; environment $\times$ time interaction, $\mathrm{F}(5,40)=0.48, p>0.05$; environment $\times$ dose $\times$ time interaction, $\mathrm{F}(5,40)=0.59, p>0.05)$.

\section{Cocaine Increases the Expression of the Immediate Early Gene zif-268 in the Striatum of SE but not of EE Mice}

As the differences in behavioral responses to cocaine could not be explained by different effects of cocaine at the presynaptic levels, we monitored the expression of Zif-268 (Beckmann and Wilce, 1997) by in situ hybridization in the striatum as a measure of reactivity to cocaine at the postsynaptic levels. Basal levels of zif-268 did not differ between SE and EE in any region examined. In addition, zif268 mRNA levels did not differ between mice chronically pretreated with cocaine $(15 \mathrm{mg} / \mathrm{kg}$ i.p) and saline pretreated controls (groups coc-sal vs sal-sal). Cocaine challenge $(10 \mathrm{mg} / \mathrm{kg}$ ) increased zif-268 mRNA levels (about 25\%) in the NAc shell and the core (but not in the caudate putamen) 
of SE mice similarly in chronically cocaine- ( $\operatorname{coc}-\operatorname{coc})$ and saline-treated (sal-coc) mice, indicating that these effects of cocaine do not undergo sensitization. In contrast, in EE mice, cocaine $(10 \mathrm{mg} / \mathrm{kg}$ i.p.) did not increase expression of zif-268 in any condition (three-way ANOVA: Shell, environment effect, $\mathrm{F}(1,37)=7.72, p<0.01$; treatment effect, $\mathrm{F}(1,37)=2.32, \quad p>0.05 ; \quad$ challenge effect, $\mathrm{F}(1,37)=5.66$, $p<0.05$; environment $\times$ treatment, $\mathrm{F}(1,37)=1.06, \quad p>0.05$; environment $\times$ challenge, $\mathrm{F}(1,37)=6.94, p<0.05$; treatment $\times$ challenge, $\quad \mathrm{F}(1,37)=0.71, \quad p>0.05 ; \quad$ environment $\times$ treatment $\times$ challenge, $\mathrm{F}(1,37)=0.10, \quad p>0.05$; Core; challenge effect, $\mathrm{F}(1,37)=16.70, p<0.01$; Caudate Putamen, Challenge effect, $\mathrm{F}(1,37)=5.28, p<0.05)$ (Figure 4).
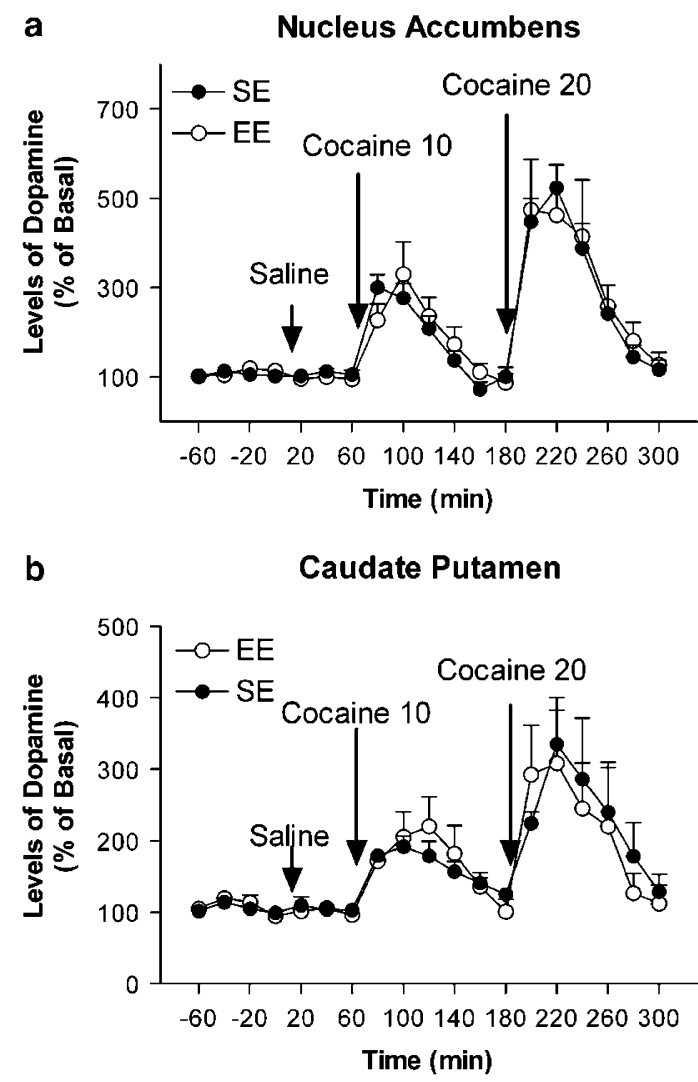

Figure 3 Cocaine-induced elevations of dopamine levels in mice reared in standard (SE) or enriched (EE) environments. Injections of 10 and $20 \mathrm{mg} / \mathrm{kg}$ of cocaine increase the extracellular levels of dopamine (a) in the nucleus accumbens and (b) in the caudate putamen to similar extent in $\mathrm{SE}$ and $\mathrm{EE}$ mice. Arrows indicate the time of injections. Results represent means \pm SEM from five to six mice.

Figure 4 Expression of zif-268 in mice reared in standard (SE) or enriched (EE) environments sensitized to cocaine. For induction of behavioral sensitization mice were injected with cocaine $(15 \mathrm{mg} / \mathrm{kg})$ or saline as in Figure 2 and injected with cocaine $(10 \mathrm{mg} / \mathrm{kg})$ or saline 30 days after the last cocaine or saline injection. Challenge injections of cocaine increase zif-268 expression in the shell (a) and core (b) of the nucleus accumbens in SE but not in EE mice. Importantly, zif-268 expression was not enhanced by sensitization. No significant change was found in the caudate putamen in SE or EE mice (c). Post-hoc Student-Newman-Keuls's test: ${ }^{*} p<0.05$ different from saline control; ${ }^{\# \#} p<0.01$ different from SE control. Results represent means \pm SEM from six mice.
EE and SE Have Opposite Effects on the Levels of Delta-Fos B Following Cocaine Administration

By western blot, we measured Delta-Fos B levels in the striatum of SE and EE mice sensitized to cocaine $(15 \mathrm{mg} / \mathrm{kg})$ and in saline controls. As previously reported (Hiroi et al, 1997), repeated administration of cocaine produced a
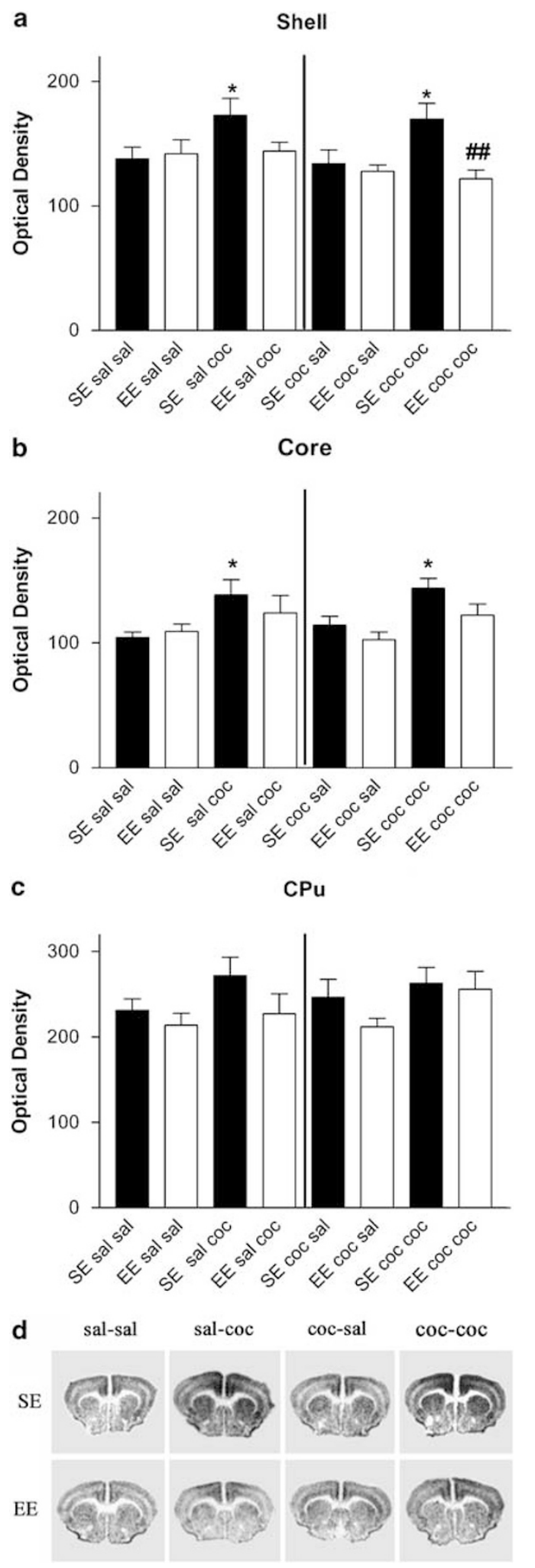


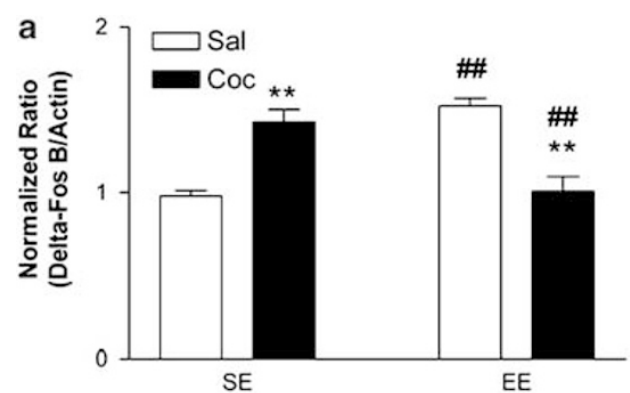

b

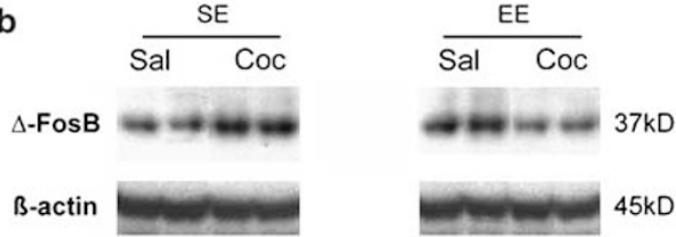

Figure 5 Levels of Delta-Fos B protein in the striatum of mice reared in standard (SE) or enriched (EE) environments sensitized to cocaine. Mice underwent the same protocol for the development of cocaine sensitization as in Figure $2 \mathrm{a}$ and were killed $18 \mathrm{~h}$ after the last cocaine or saline injection. EE mice show higher basal levels of Delta-Fos B than SE mice. Importantly, repeated administration of cocaine induced an increase of Delta-Fos $B$ levels in SE and a decrease in EE mice. (a) Graphical representation of group means and (b) representative immunoblots. Post-hoc StudentNewman-Keuls's test: ${ }^{* *} p<0.0$ I different from saline control; ${ }^{\# \#} p<0.0$ I different from SE control. Results represent means \pm SEM from eight mice.

significant increase in Delta-Fos B levels in the striatum of SE mice (about 40\%). Interestingly, levels of Delta-Fos B in the striatum of saline-treated EE mice were elevated compared to saline-treated SE mice (about 50\%) and were comparable to cocaine-treated SE mice. Surprisingly, in EE mice cocaine did not produce an increase but rather a decrease in Delta-Fos B levels (two-way ANOVA, environment effect, $\mathrm{F}(1,44)=2.15, \quad p>0.05 ;$ treatment effect, $\mathrm{F}(1,44)=0.28, \quad p>0.05$; environment $\times$ treatment effect, $\mathrm{F}(1,44)=21.97, p<0.0001)$ (Figure 5).

\section{DISCUSSION}

In this study, we found that EE mice are protected against the effects of cocaine. EE mice develop less conditioned place preferences for compartments associated with cocaine injections and are less sensitive to the activating effects of cocaine in a sensitization paradigm than SE mice. In addition, cocaine-induced increases in dopamine levels in the striatum do not differ between EE and SE mice, whereas ventral striatal neurons are activated by cocaine in SE but not in EE mice, as measured by expression of the immediate early gene zif-268. Finally, we found that saline-treated EE mice have higher striatal levels of Delta-Fos B than salinetreated SE mice and that, whereas repeated administration of cocaine increases Delta-Fos B levels in the striatum of SE mice, it decreases Delta-Fos B levels in the striatum of EE mice. These results suggest that exposure to positive environmental conditions during early stages of life can greatly influence brain functioning and can provide protection against the effects of addictive drugs.

In a previous study, we found that the activating effects of an acute administration of cocaine were reduced by exposure to EE (Bezard et al, 2003). Here, we show that the rewarding effects of cocaine are also diminished in EE mice. In addition, EE reduce the activating effects of repeated administrations of cocaine. Indeed, in a behavioral sensitization paradigm, EE mice show reduced locomotion both during the development and the expression of behavioral sensitization. Although the validity of behavioral sensitization models to study drug addiction in humans is debated (Lecca et al, 2007), behavioral sensitization is considered an important preclinical tool to study the increases in the effects of drugs and the neuroadaptations that take place in the brain upon repeated administration of cocaine (Vanderschuren and Kalivas, 2000; Berridge, 2007; Bradberry, 2007). In our study, the rate of sensitization was similar between SE and EE mice with cocaine-treated mice having an average increase of $100 \%$ in locomotor counts as compared to the first day of cocaine exposure, whereas the sustained reduction of the effects of cocaine indicates that EE mice are protected against the effects of this drug. In a previous study, it was shown that rats reared in EE are less sensitive to the discriminative effects of cocaine (Fowler et al, 1993). In addition, in rats, EE decrease the rewarding effects of amphetamine in a self-administration paradigm (but not in a conditioned place preference paradigm) (Bowling and Bardo, 1994; Bardo et al, 2001; Green et al, 2002) and the activating effects of amphetamine (Bowling et al, 1993; Bardo et al, 1995) or nicotine (Green et al, 2003). However, in those studies, control groups for the effects of environmental enrichment were animals reared and housed in impoverished/isolated conditions. Whereas such controls may have helped magnifying the effects of EE, in our opinion, they do not represent a proper control to extrapolate the effects of environmental enrichment because of the known important behavioral, neurochemical, and molecular alterations produced by social isolation ( $\mathrm{Lu}$ et al, 2003; Van den Buuse et al, 2003). Thus, our model, which compares enriched to standard housing conditions, has the advantage to provide direct and uncontroversial information of the influences of enrichment on the effects of cocaine. A recent study comparing mice reared in $\mathrm{EE}$ to mice reared in SE has found that EE mice show less activation and less place preference to morphine than SE mice (Xu et al, 2007).

Cocaine elevates dopamine levels by binding to the dopamine membrane transporter (DAT) and preventing dopamine reuptake by presynaptic terminals (Jaber et al, 1997) and these dopamine elevations in the NAc are considered central in the mediation of the reinforcing effects of psychostimulants (Di Chiara and Bassareo, 2007). Given that previous studies have shown reduced DAT levels in mice reared in EE (Bezard et al, 2003), we expected that the reduced effects of cocaine were related to a deficit in its ability to elevate dopamine in the NAc. In contrast, we found that the levels of dopamine under basal conditions and after cocaine administration did not differ between EE and SE. It is possible that, although significant, reductions of about $20 \%$ in DAT levels (Bezard et al, 2003) were not sufficient to alter cocaine-induced effects. It is also possible that given the chronic nature of environmental enrichment, neuronal adaptations occur in EE mice that compensate the decrease in DAT. For example, it has been shown that in DAT knockout mice, cocaine induces normal increases in 
dopamine accumbal levels through an action on noradrenaline transporter (Carboni et al, 2001).

We have previously shown that acute cocaine $(20 \mathrm{mg} / \mathrm{kg})$ increases c-fos levels in dorsolateral striatum in EE mice and in the ventromedial striatum in SE mice (Bezard et al, 2003). Here, in the same cocaine sensitization paradigm used for our behavioral experiments, we have measured mRNA levels of zif-268, another immediate early gene, whose expression is tightly correlated with cellular activation and synaptic plasticity (Beckmann and Wilce, 1997). Acute administration of cocaine increases the expression of zif-268 in the ventral and dorsal striatum in rats (Hope et al, 1992; Moratalla et al, 1992; Thiriet et al, 2002) and in mice (Brami-Cherrier et al, 2005). In addition, in mice genetically lacking zif-268 behavioral sensitization and conditioned place preferences are dramatically reduced (Valjent et al, 2006). Finally, injections of zif-268 antisense oligodeoxynucleotides in the basolateral amygdala disrupt the reconsolidation of drug-related memories and reduces cocaine-seeking behavior (Lee et al, 2005). Consistent with those studies, we found that zif-268 expression in the shell and core of the NAc was induced by cocaine administration in SE mice to the same extent in sensitized and nonsensitized mice. In contrast, in EE mice cocaine did not induce zif-268 expression in the NAc. Thus, the reduced expression of zif-268 in response to cocaine found in EE mice may participate to the reduced behavioral effects of cocaine in these mice. Several mechanisms could explain how similar levels of extracellular dopamine induced differential reactivity to cocaine in striatal neurons. For example, changes in dopamine receptors availability or functionality might account for the reduced response to cocaine. However, previous studies have failed to show a significant effect of environmental enrichment on D1 and D2 binding (Bardo and Hammer, 1991) and mRNA expression (Bezard et al, 2003). Future studies are needed to investigate whether other systems such as the glutamate system (Beckmann and Wilce, 1997), at the presynaptic or postsynaptic level, are involved in the protective effects of environmental enrichment.

Delta-Fos B is a member of the Fos family of transcription factors. In contrast to the other Fos proteins, Delta-Fos B is induced to only a small degree in response to acute drug administration but because of its unique stability, after repeated drug administration, Delta-Fos B gradually accumulates in the striatum and stays elevated for weeks or months after discontinuation of drug exposure (Hope et al, 1994; Chen et al, 1995; Moratalla et al, 1996; Hiroi et al, 1997). Thus, it has been hypothesized that Delta-Fos B functions as a sustained molecular switch that mediates some of the more persistent adaptations of the brain that underlie addiction (McClung et al, 2004). Importantly, striatal Delta-Fos B has been shown to be increased not only by drugs of addiction but also by nonaddictive drugs, such as antipsychotics as well as environmental manipulations such as exposure to stress (McClung et al, 2004). In our study, environmental stimulation per se increased striatal levels of Delta-Fos B in saline-treated mice. This increase is likely due to the constant activation of striatal neurons produced by environmental enrichment. A previous study has shown that wheel running increases striatal levels of Delta-Fos B in rats (Werme et al, 2002). Thus, it is possible that wheel running, which is a constant part of our EE, was, at least in part, responsible for increases in Delta-Fos B. Interestingly, a recent study has found that Delta-Fos B activation parallels and may be responsible for the increases in spine density subsequent to chronic cocaine administration (Lee et al, 2006). Given that EE increase striatal dendritic arborization (Kolb et al, 2003), Delta-Fos B may be involved in these structural modifications.

Elevations in Delta-Fos B levels are generally believed to be one of the mechanisms responsible to the sensitized reactions to cocaine (McClung and Nestler, 2003), whereas in our study, EE mice that had higher basal levels of DeltaFos B showed reduced responses to cocaine. Although somewhat unexpected, these results are in agreement with the work of Hiroi et al. (1997) who found that the constitutive Fos B knock-out mice are more sensitive to the effects of cocaine than wild-type control. This supports the view that the influences of Delta-Fos B on subsequent behavioral, neurochemical, and molecular effects of addictive drugs depend on several factors, such as the duration of the increase in Delta-Fos B levels (McClung and Nestler, 2003) and the striatal type neurons where Delta-Fos B is actually increased (McClung et al, 2004).

Surprising findings of this study were that when cocaine was administered to EE mice, it decreased, instead of increasing, Delta-Fos B striatal levels indicating that EE induces a form of neuronal plasticity that dramatically alters the effects of subsequent cocaine administration. To our knowledge, this is the first study showing that in vivo manipulations can induce decreases in striatal levels of Delta-Fos B. Interestingly, in vitro experiments have recently shown that the exceptional resistance of Delta-Fos $\mathrm{B}$ to metabolic degradation appears to depend on the phosphorylation of a serine residue (Ulery et al, 2006). Although we could not test this hypothesis, it is intriguing to speculate that in EE mice repeated administration of cocaine alters the activity of kinases or phosphatases and results in the dephosphorylation of Delta-Fos B.

In conclusion, in this study we demonstrate that environmental stimulation during early stages of life provides protection against the abuse-related effects of cocaine. This protection appears to be mediated by a reduced activation of striatal neurons by cocaine and by dramatic changes in the neuronal adaptations usually observed after repeated cocaine administration. These results support the hypothesis that positive life experiences during critical periods, such as the adolescence decrease the sensitivity to drugs of abuse and the vulnerability to addiction.

\section{ACKNOWLEDGEMENTS}

We thank Dr M Iadarola (NIDCR, NIH, USA) for generously providing Fos antibody. We thank B Merceron for technical assistance and JP Poindessault for help with figures. This study was supported by CNRS, University of Poitiers, Fondation pour la Recherche Médicale (FRM, 2003), Mission Interministérielle de la Lutte contre les Drogues et la Toxicomanie (MILDT-INSERM, 2006-2007) and Région Poitou Charentes (2003). R El Rawas is a recipient of a CNRS PhD fellowship (BDI-PED, 2005-2008). 


\section{DISCLOSURE/CONFLICT OF INTEREST}

The authors declare that except for finance received from their primary employer no financial support or compensation has been received from any individual or corporate entity over the past 3 years for research or professional service and there are no personal financial holdings that could be perceived as constituting a potential conflict of interests.

\section{REFERENCES}

Bardo MT, Bowling SL, Rowlett JK, Manderscheid P, Buxton ST, Dwoskin LP (1995). Environmental enrichment attenuates locomotor sensitization, but not in vitro dopamine release, induced by amphetamine. Pharmacol Biochem Behav 51: 397-405.

Bardo MT, Hammer Jr RP (1991). Autoradiographic localization of dopamine D1 and D2 receptors in rat nucleus accumbens: resistance to differential rearing conditions. Neuroscience 45: 281-290.

Bardo MT, Klebaur JE, Valone JM, Deaton C (2001). Environmental enrichment decreases intravenous self-administration of amphetamine in female and male rats. Psychopharmacology (Berl) 155: 278-284.

Beckmann AM, Wilce PA (1997). Egr transcription factors in the nervous system. Neurochem Int 31: 477-510; discussion 517-476.

Berke JD, Hyman SE (2000). Addiction, dopamine, and the molecular mechanisms of memory. Neuron 25: 515-532.

Berridge KC (2007). The debate over dopamine's role in reward: the case for incentive salience. Psychopharmacology (Berl) 191: 391-431.

Bezard E, Dovero S, Belin D, Duconger S, Jackson-Lewis V, Przedborski S et al (2003). Enriched environment confers resistance to 1-methyl-4-phenyl-1,2,3,6-tetrahydropyridine and cocaine: involvement of dopamine transporter and trophic factors. J Neurosci 23: 10999-11007.

Bowling SL, Bardo MT (1994). Locomotor and rewarding effects of amphetamine in enriched, social, and isolate reared rats. Pharmacol Biochem Behav 48: 459-464.

Bowling SL, Rowlett JK, Bardo MT (1993). The effect of environmental enrichment on amphetamine-stimulated locomotor activity, dopamine synthesis and dopamine release. Neuropharmacology 32: 885-893.

Bradberry CW (2007). Cocaine sensitization and dopamine mediation of cue effects in rodents, monkeys, and humans: areas of agreement, disagreement, and implications for addiction. Psychopharmacology (Berl) 191: 705-717.

Brami-Cherrier K, Valjent E, Herve D, Darragh J, Corvol JC, Pages C et al (2005). Parsing molecular and behavioral effects of cocaine in mitogen- and stress-activated protein kinase-1deficient mice. J Neurosci 25: 11444-11454.

Brenhouse HC, Stellar JR (2006). c-Fos and deltaFosB expression are differentially altered in distinct subregions of the nucleus accumbens shell in cocaine-sensitized rats. Neuroscience 137: 773-780.

Carboni E, Spielewoy C, Vacca C, Nosten-Bertrand M, Giros B, Di Chiara G (2001). Cocaine and amphetamine increase extracellular dopamine in the nucleus accumbens of mice lacking the dopamine transporter gene. J Neurosci 21: RC141: 141-144.

Chen J, Nye HE, Kelz MB, Hiroi N, Nakabeppu Y, Hope BT et al (1995). Regulation of delta FosB and FosB-like proteins by electroconvulsive seizure and cocaine treatments. Mol Pharmacol 48: 880-889.

Cunningham CL, Gremel CM, Groblewski PA (2006). Druginduced conditioned place preference and aversion in mice. Nat Protoc 1: 1662-1670.
Di Chiara G, Bassareo V (2007). Reward system and addiction: what dopamine does and doesn't do. Curr Opin Pharmacol 7: 69-76.

Fowler SC, Johnson JS, Kallman MJ, Liou JR, Wilson MC, Hikal AH (1993). In a drug discrimination procedure isolation-reared rats generalize to lower doses of cocaine and amphetamine than rats reared in an enriched environment. Psychopharmacology (Berl) 110: $115-118$.

Gerfen CR (2000). Molecular effects of dopamine on striatalprojection pathways. Trends Neurosci 23: S64-S70.

Goeders NE (2002). Stress and cocaine addiction. J Pharmacol Exp Ther 301: 785-789.

Green TA, Cain ME, Thompson M, Bardo MT (2003). Environmental enrichment decreases nicotine-induced hyperactivity in rats. Psychopharmacology (Berl) 170: 235-241.

Green TA, Gehrke BJ, Bardo MT (2002). Environmental enrichment decreases intravenous amphetamine self-administration in rats: dose-response functions for fixed- and progressive-ratio schedules. Psychopharmacology (Berl) 162: 373-378.

Hiroi N, Brown JR, Haile CN, Ye H, Greenberg ME, Nestler EJ (1997). FosB mutant mice: loss of chronic cocaine induction of Fos-related proteins and heightened sensitivity to cocaine's psychomotor and rewarding effects. Proc Natl Acad Sci USA 94: 10397-10402.

Hope B, Kosofsky B, Hyman SE, Nestler EJ (1992). Regulation of immediate early gene expression and AP-1 binding in the rat nucleus accumbens by chronic cocaine. Proc Natl Acad Sci USA 89: $5764-5768$.

Hope BT (1998). Cocaine and the AP-1 transcription factor complex. Ann NY Acad Sci 844: 1-6.

Hope BT, Nye HE, Kelz MB, Self DW, Iadarola MJ, Nakabeppu Y et al (1994). Induction of a long-lasting AP-1 complex composed of altered Fos-like proteins in brain by chronic cocaine and other chronic treatments. Neuron 13: 1235-1244.

Jaber M, Dumartin B, Sagne C, Haycock JW, Roubert C, Giros B et al (1999). Differential regulation of tyrosine hydroxylase in the basal ganglia of mice lacking the dopamine transporter. Eur $J$ Neurosci 11: 3499-3511.

Jaber M, Jones S, Giros B, Caron MG (1997). The dopamine transporter: a crucial component regulating dopamine transmission. Mov Disord 12: 629-633.

Kolb B, Gorny G, Li Y, Samaha AN, Robinson TE (2003). Amphetamine or cocaine limits the ability of later experience to promote structural plasticity in the neocortex and nucleus accumbens. Proc Natl Acad Sci USA 100: 10523-10528.

Kreek MJ, Nielsen DA, Butelman ER, LaForge KS (2005). Genetic influences on impulsivity, risk taking, stress responsivity and vulnerability to drug abuse and addiction. Nat Neurosci 8: 1450-1457.

Lecca D, Cacciapaglia F, Valentini V, Acquas E, Di Chiara G (2007). Differential neurochemical and behavioral adaptation to cocaine after response contingent and noncontingent exposure in the rat. Psychopharmacology (Berl) 191: 653-667.

Lee JL, Di Ciano P, Thomas KL, Everitt BJ (2005). Disrupting reconsolidation of drug memories reduces cocaine-seeking behavior. Neuron 47: 795-801.

Lee KW, Kim Y, Kim AM, Helmin K, Nairn AC, Greengard P (2006). Cocaine-induced dendritic spine formation in D1 and D2 dopamine receptor-containing medium spiny neurons in nucleus accumbens. Proc Natl Acad Sci USA 103: 3399-3404.

Lu L, Shepard JD, Hall FS, Shaham Y (2003). Effect of environmental stressors on opiate and psychostimulant reinforcement, reinstatement and discrimination in rats: a review. Neurosci Biobehav Rev 27: 457-491.

Marinelli M, Piazza PV (2002). Interaction between glucocorticoid hormones, stress and psychostimulant drugs. Eur J Neurosci 16: 387-394. 
McClung CA, Nestler EJ (2003). Regulation of gene expression and cocaine reward by CREB and DeltaFosB. Nat Neurosci 6: 1208-1215.

McClung CA, Ulery PG, Perrotti LI, Zachariou V, Berton O, Nestler EJ (2004). DeltaFosB: a molecular switch for long-term adaptation in the brain. Brain Res Mol Brain Res 132: 146-154.

Moratalla R, Elibol B, Vallejo M, Graybiel AM (1996). Networklevel changes in expression of inducible Fos-Jun proteins in the striatum during chronic cocaine treatment and withdrawal. Neuron 17: 147-156.

Moratalla R, Robertson HA, Graybiel AM (1992). Dynamic regulation of NGFI-A (zif268, egr1) gene expression in the striatum. J Neurosci 12: 2609-2622.

Nithianantharajah J, Hannan AJ (2006). Enriched environments, experience-dependent plasticity and disorders of the nervous system. Nat Rev Neurosci 7: 697-709.

Paxinos G, Franklin KBJ (2001). The Mouse Brain in Stereotoxic Coordinates, Second Edition, Academic Press, San Diego.

Robinson TE, Berridge KC (2003). Addiction. Annu Rev Psychol 54: 25-53.

Rouge-Pont F, Marinelli M, Le Moal M, Simon H, Piazza PV (1995). Stress-induced sensitization and glucocorticoids. II. Sensitization of the increase in extracellular dopamine induced by cocaine depends on stress-induced corticosterone secretion. J Neurosci 15: 7189-7195.

Sinha R (2001). How does stress increase risk of drug abuse and relapse? Psychopharmacology (Berl) 158: 343-359.

Solinas M, Justinova Z, Goldberg SR, Tanda G (2006). Anandamide administration alone and after inhibition of fatty acid amide hydrolase (FAAH) increases dopamine levels in the nucleus accumbens shell in rats. J Neurochem 98: 408-419.

Thiriet N, Aunis D, Zwiller J (2002). The nitric oxide releasing agent sodium nitroprusside modulates cocaine-induced immediate early gene expression in rat brain. Ann NY Acad Sci 965: 47-54.

Ulery PG, Rudenko G, Nestler EJ (2006). Regulation of DeltaFosB stability by phosphorylation. J Neurosci 26: 5131-5142.

Valjent E, Aubier B, Corbille AG, Brami-Cherrier K, Caboche J, Topilko $P$ et al (2006). Plasticity-associated gene Krox24/Zif268 is required for long-lasting behavioral effects of cocaine. J Neurosci 26: 4956-4960.

Van den Buuse M, Garner B, Koch M (2003). Neurodevelopmental animal models of schizophrenia: effects on prepulse inhibition. Curr Mol Med 3: 459-471.

van Praag H, Kempermann G, Gage FH (2000). Neural consequences of environmental enrichment. Nat Rev Neurosci 1: 191-198.

Vanderschuren LJ, Kalivas PW (2000). Alterations in dopaminergic and glutamatergic transmission in the induction and expression of behavioral sensitization: a critical review of preclinical studies. Psychopharmacology (Berl) 151: 99-120.

Werme M, Messer C, Olson L, Gilden L, Thoren P, Nestler EJ et al (2002). Delta FosB regulates wheel running. J Neurosci 22: $8133-8138$.

Will B, Galani R, Kelche C, Rosenzweig MR (2004). Recovery from brain injury in animals: relative efficacy of environmental enrichment, physical exercise or formal training (1990-2002). Prog Neurobiol 72: 167-182.

Wurbel H (2001). Ideal homes? Housing effects on rodent brain and behaviour. Trends Neurosci 24: 207-211.

Xu Z, Hou B, Gao Y, He F, Zhang C (2007). Effects of enriched environment on morphine-induced reward in mice. Exp Neurol 204: 714-719.

Yano M, Steiner H (2005). Methylphenidate (Ritalin) induces Homer 1a and zif 268 expression in specific corticostriatal circuits. Neuroscience 132: 855-865.

Supplementary Information accompanies the paper on the Neuropsychopharmacology website (http://www.nature.com/npp) 